\title{
Global Patterns of Gene Regulation Associated with the Development of Ectomycorrhiza Between Birch (Betula pendula Roth.) and Paxillus involutus (Batsch) Fr.
}

\author{
Antoine Le Quéré, Derek P. Wright, Bengt Söderström, Anders Tunlid, and Tomas Johansson \\ Department of Microbial Ecology, Ecology Building, Lund University, SE-223 62 Lund, Sweden \\ Submitted 30 August 2004. Accepted 18 February 2005.
}

\begin{abstract}
The formation of ectomycorrhizal (ECM) root tissue is characterized by distinct morphological and developmental stages, such as preinfection and adhesion, mantle, and Hartig net formation. The global pattern of gene expression during these stages in the birch (Betula pendula)-Paxillus involutus ECM association was analyzed using cDNA microarrays. In comparison with nonsymbiotic conditions, 251 fungal (from a total of 1,075) and 138 plant $(1,074$ in total) genes were found to be differentially regulated during the ECM development. For instance, during mantle and Hartig net development, there were several plant genes upregulated that are normally involved in defense responses during pathogenic fungal challenges. These responses were, at later stages of ECM development, found to be repressed. Other birch genes that showed differential regulation involved several homologs that usually are implicated in water permeability (aquaporins) and water stress tolerance (dehydrins). Among fungal genes differentially upregulated during stages of mantle and Hartig net formation were homologs putatively involved in mitochondrial respiration. In fully developed ECM tissue, there was an upregulation of fungal genes related to protein synthesis and the cytoskeleton assembly machinery. This study highlights complex molecular interactions between two symbionts during the development of an ECM association.
\end{abstract}

Additional keywords: stress response, symbiosis.

Ectomycorrhizas (ECM) are symbiotic associations between soil fungi and the fine roots of woody plants. ECM fungi include at least 5,000 species, primarily basidiomycetes, and they form symbiotic relationships with diverse species of plants, including conifers and many families of angiosperms (Hibbett et al. 2000; Malloch et al. 1980). In these ecologically very important interactions, the fungus provides the plant with

Corresponding author: T. Johansson: Telephone: +46 46-222 45 49; Fax: +46 46-222 41 58; E-mail: tomas.johansson@mbioekol.lu.se

Nucleotide sequence data for all EST clones described are available from the NCBI dbEST database. The microarray design (accession number AMEXP-92) and the raw dataset (accession number E-MEXP-180) are available from the EMBL-EBI ArrayExpress database.

* The $\boldsymbol{e}$-Xtra logo stands for "electronic extra" and indicates the HTML abstract available on-line contains supplemental tables, listing selected fungal and plant genes showing significant differential regulation, not included in the print edition. mineral nutrients, which, in return, supply the fungus with photosynthetically derived carbohydrates (Smith and Read 1997). The exchange of nutrients occurs in a specific symbiotic tissue that is formed at the interface between the fungus and the plant. Despite the large number of fungal and plant species that are able to form ECM, the organization of this tissue shows common features (Brun et al. 1995; Horan et al. 1988; Malajczuk et al. 1990; Smith and Read 1997; Tagu et al. 2002). This suggests the presence of general program for controlling the development and maintenance of the symbiotic tissue.

After a preinfection and adhesion stage that probably involves communication of compatibility factors, the fungal mycelium surrounding the root undergoes a rapid transformation in morphology; the hyphae swell and branch heavily. A mantle is formed, which isolates the surface of the root from its substrate. Continued colonization of the root surface is followed by the inhibition and disappearance of pre-existing root hairs. From the inner zone of the mantle, the apoplast of the epidermal or cortical root cells is penetrated by hyphae, which forms the so-called Hartig net. During formation of the Hartig net, the fungal cells proliferate between the root cells and the cell walls, and plasma membranes become highly invaginated. The cells become multinucleated and rich in mitochondria and endoplasmatic reticulum, suggesting a high metabolic activity in these cells. This is the site in which the exchange of carbon and nutrients between the two organisms is thought to occur (Barker et al. 1998; Tagu et al. 2002). In some angiosperms, the shape and orientation of the root cells change during the development of the Hartig net; thus, the root apoplast is drastically modified during the establishment of the ECM symbiosis (Smith and Read 1997; Tagu et al. 2002). From the mantle, fungal hyphae extend outwards into the surrounding soil volume for exploration and translocation of nutrients back to the plant root.

It is well known that the developmental transitions leading to the formation of ECM tissue are accompanied by changes in gene expression and protein synthesis. For example, a number of cell-wall proteins, including hydrophobins, mannoproteins, and acidic polypeptides, are regulated during ECM development (Laurent et al. 1999; Martin et al. 1999; Tagu and Martin 1996; Tagu et al. 1996, 2001). Other fungal proteins that are known to be regulated during ECM formation are components of the cytoskeleton (Carnero Diaz et al. 1996; Niini et al. 1996), ras GTPases (Sundaram et al. 2001), and hexose transporters (Nehls et al. 2001). However, it can be expected that the development of ECM tissue will affect the expression of a large number of plant and fungal genes. Recently, several 
attempts have been made to analyze such global patterns of gene expression (Duplessis et al. 2005; Johansson et al. 2004; Le Quéré et al. 2004; Menotta et al. 2004; Morel et al. 2005; Peter et al. 2003; Podila et al. 2002; Voiblet et al. 2001). In a pioneer study using cDNA arrays for analysis of the PisolithusEucalyptus ECM association (Voiblet et al. 2001), it was shown that about $17 \%$ of the genes represented on the array (850 in total) were differentially expressed in the ECM tissue. In an initial cDNA microarray study of the ECM association between Paxillus involutus and birch (Betula pendula), approximately $10 \%$ of the fungal and plant genes (2,284 reporters in total) were differentially regulated in the ECM root tissue (Johansson et al. 2004). A number of these transcripts had sequence similarities to genes known to be involved in plant and fungal morphogenesis and metabolism. In both of these studies, the gene expression in ECM tissue was compared with expression under non-ECM conditions.

In this work, we have traced fungal and plant gene expression during the development of an ECM association between Paxillus involutus and birch (B. pendula). Five timepoints were selected that coincide with distinct stages in the development of the ECM tissue between Paxillus involutus and birch (Brun et al. 1995). The experimental design also included reference tissue grown axenically and in parallel, for the purpose of detecting genes that are differentially regulated during the timecourse but which are not related to the ECM interaction. For the evaluation of data, we applied statistical filtering (mixed-model analysis of variance [ANOVA]) to rank the effects of time and tissue on transcription (Wolfinger et al. 2001). This investigation reveals novel features on the development of an ECM interaction, and the results will be discussed in the context of symbiotic and pathogenic interactions between fungi and plants. Special attention will be devoted to a recently published investigation that describes a relatively similar study on the development of ECM in the Eucalyptus globules-Pisolithus microcarpus association (Duplessis et al. 2005).

\section{RESULTS}

\section{Developmental stages.}

As previously observed (Brun et al. 1995), Paxillus involutus rapidly colonized the roots of $B$. pendula. Fungal colonization of the root system could be detected within 12 to $24 \mathrm{~h}$ after contact (Fig. 1). At this stage of preinfection, hyphae were sparsely present along the root and the plant root hairs could still be seen. After two days of contact, the formation of a mantle had been started, although the hyphae remained sparse and unorganized and the presence of root hairs was still evident. In particular, there was an accumulation of poorly aggregated hyphae at the apical region of the main root axis. In the days that followed, newly emerging lateral roots became completely enveloped by a mantle of fungal hyphae that formed two distinct layers, one inner layer of closely aggregated hyphae and one outer layer consisting of sparse, less well-organized hyphae. After four days, an aggregate of dense fungal hyphae had completely enveloped the root system and the first sign of the Hartig net formation was observed. At this stage, the morphology of the colonized root system differed markedly from the uncolonized reference material. There were three to five newly emerging lateral roots per plant when challenged with the ECM fungus versus one to three in the control plants. Furthermore, contrary to the free-living seedlings, these lateral roots remained short during the entire timecourse. After 8 to 10 days of contact, a thick mantle had developed and the Hartig net could clearly be recognized. After 14 days of contact, the Hartig net was fully established along the length of the root. The maturation of the Hartig net was characterized by a transition from a para-epidermal to a peri-epidermal structure in which fungal hyphae enveloped the plant epidermal cells entirely, forming a peri-epidermal Hartig net. After 21 days, some of the root tips had produced side branches but no other major morphological changes were observed (Fig. 1).

\section{Experimental design.}

Our experimental design consisted of 20 cDNA microarrays, involving 40 separate labeling reactions (Fig. 2). ECM tissue was analyzed at five different timepoints after initial contact between the symbionts had occurred. The experimental design also included reference tissue grown axenically in parallel during the timecourse, with the purpose of detecting differential regulation of genes not related to the ECM interaction. For the ECM tissue, we sequentially and directly compared timepoints, including one loop-back hybridization, whereas the reference tissue was directly compared to ECM tissue within each timepoint (Fig. 2). Three biological replicates were used for the ECM tissue, whereas two replicates were used for the reference tissue.

\section{Statistical filtering.}

The statistical approach we used served two purposes: i) normalization of the data to remove systemic biases that may have affected all genes simultaneously, such as differences in the amount of RNA that was labeled for a particular replicate of a treatment, and ii) assessment of the contribution of biological and experimental sources of error to the variation in the expression of each individual gene (Wolfinger et al. 2001). We analyzed fluorescence levels with the purpose of establishing whether the level of expression of each gene relative to the sample mean of the labeling reaction varied according to time, tissue, or both. The analysis included two sequential ANOVA (Jin et al. 2001; Wolfinger et al. 2001). This procedure uses differences in normalized expression levels rather than ratios, as a unit for analysis of expression differences. The statistical model for each reporter or gene simultaneously fits the effects of the treatments of interest across the entire experiment, allowing direct comparisons of the magnitude of the effects caused by each treatment and interactions among treatments.

The significance of each of the three fixed effects of biological interest (time, tissue, time $\times$ tissue) plus the dye effect for each gene are given in Table 1. At a significance level of $P<$ 0.05 , there is a statistical support for effects of time on 43 fungal genes (4.1\% of the sample) and 51 plant genes $(4.8 \%)$. For tissue effects, there is evidence that 45 fungal genes $(4.3 \%)$ and 19 plant genes $(1.8 \%)$ are significant. The numbers of genes showing time $\times$ tissue interactions are $388(37.3 \%)$ for fungal genes and $302(28.5 \%)$ for plant genes. In Figure 3, comparisons between ECM and reference tissue at the different timepoints are shown, both for fungal and plant genes. The comparisons are presented as Volcano plots showing degree of significance versus magnitude of effect. Bonferroni correction, based on a $P<0.05$ for the almost 11,000 tests carried out, resulted in an experiment-wise significance value of $4.8 \times 10^{-6}$ (corresponding to a value of 5.3 on the y-axis), which was used as cut-off for both the fungal and plant datasets.

From this comparison of ECM and reference tissue at each timepoint, we collected genes being significantly differentially expressed after applying an experiment-wise significance threshold (Table 2). Among these, we filtered for a nonredundant set of genes, i.e., genes being significantly differentially regulated at no less than one of the timepoints, after comparing the ECM and reference tissue. Among these, we found 251 fungal genes (24.1\% of those sampled) and 138 plant genes ( $13 \%$ of those sampled). 



-



Fig. 1. Stages of development in the ectomycorrhizal (ECM) interaction between Paxillus involutus and Betula pendula. Left panels, macroscopic views of the development of ECM root tips over time, starting at day 0 and ending at day 21. Birch seedlings were placed on a mycelial mat that had been grown on a cellophane-covered agar plate. Arrows indicate the root apical region and lateral roots that developed into ECM root tips. Right panels, microscopic views showing transverse sections of ECM root tips at different stages of development. At day 2, fungal hyphae have started to aggregate around the root tip, but this primary mantle remains loose and is easily separated from the root (arrow). At day 4, a high density of fungal hyphae is visible around the root tips as the mantle is forming. Two layers can be distinguished in the mantle, an inner layer consisting of apparently more closely adhered hyphae and an outer layer with more sparse hyphae (double-headed arrows). Note that the fungal hyphae have started to penetrate between the root epidermal cells (arrows). On day 8, the Hartig net has reached the anticlinal walls of the cortical root cells (arrows). On day 14, the Hartig net is fully established, i.e., the epidermal cells are fully surrounded by fungal hyphae (arrows). No major structural changes were observed on day 21, but a detectable labyrinthine structure produced from hyphal branching (arrow) indicates that the plant epithelial cells are extensively enveloped by fungal hyphae. 


\section{Cluster analysis.}

To organize the significantly differentially expressed genes into interpretable units, we used k-means clustering (Figs. 4 and 5 ). For the cluster analysis, we omitted the day-21 data since, for a number of genes, values were missing for either the ECM or reference tissue. We also discarded a fraction of fungal (45 of 251) and plant (35 of 138) genes that, although shown to be significantly differentially regulated, were found to lack data for one or more of the remaining four timepoints, due in most cases to low expression levels (the preprocessing of raw data is discussed below). The number of preset clusters for clustering was tested for both the plant and the fungal dataset. By setting the number of clusters to seven and nine, respectively, for the plant and fungal data, we achieved a reasonable resolution between clusters. Increasing the number of clusters did not produce any fundamentally different patterns. The clusters are defined in the legends to Figs. 4 and 5. Among the various patterns of coregulation observed, expression and repression of genes during the stages of mantle and Hartig net formation (4 and 8 days) were specifically of interest. Although fine differences could be observed between clusters, several clusters contained fungal genes that were either significantly upregulated (Fig. 4, clusters A to D) or downregulated (Fig. 4, clusters $\mathrm{H}$ and I) during mantle and
Hartig net formation. Similarly, clustering of the plant genes showed that several clusters contained genes significantly upregulated (Fig. 5, clusters A to C) or downregulated (Fig. 5, clusters $\mathrm{F}$ and $\mathrm{G}$ ) during mantle and Hartig net formation.

Quantitative polymerase chain reaction (QPCR) analysis.

For independent validation of microarray data, QPCR analyses were performed on five target genes (Table 3; Fig. 6) in samples representing ECM tissue for the three biological replicates at the five timepoints. One of these five targets was used as a normalizer to relatively quantify the fold difference in expression levels for the target and the normalizer gene at each timepoint. From comparisons of QPCR and cDNA microarray data, there was an overall agreement between the two different methods in estimating fold differences in expression levels in all five timepoints, except for the micA and hetCl comparison (Fig. 6), in which discrepancies were observed for the two last timepoints.

\section{DISCUSSION}

Despite the fact that the biological material used here were not entirely synchronized and despite the existence of averag-

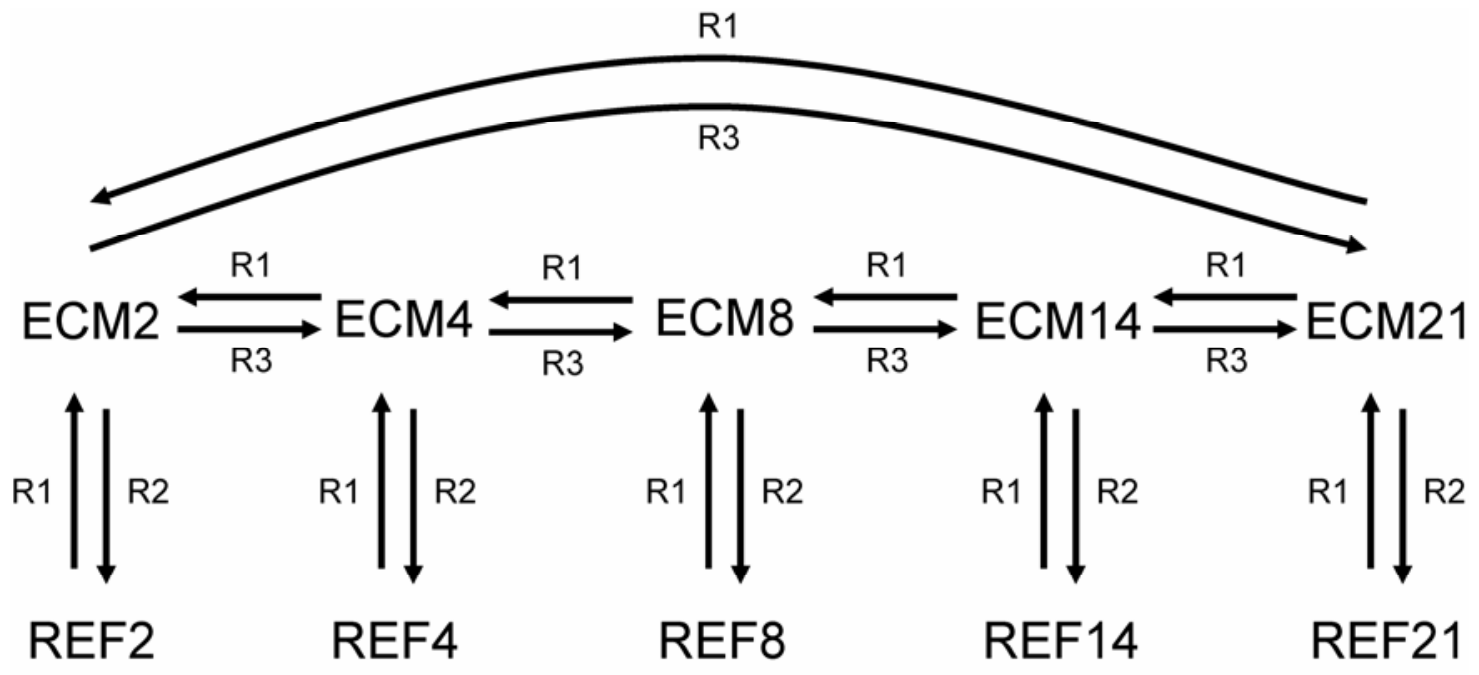

\section{$\mathrm{Cy} 5 \longrightarrow \mathrm{Cy} 3$}

Fig. 2. Diagram indicating the experimental design for the timecourse sampling during the development of the ectomycorrhizal (ECM) interaction between Paxillus involutus and Betula pendula. Each arrow specifies one microarray hybridization, with the arrowhead indicating the sample labeled with Cy3. The ECM tissue was sampled at five different timepoints, 2 (ECM2), 4 (ECM4), 8 (ECM8), 14 (ECM14), and 21 days (ECM21) after synthesis. Hybridizations to reference tissue for each timepoint were also included (REF2, REF4, REF8, REF14 and REF21). The experimental design included three biological replicates for the ECM tissue and two replicates for the reference tissue (R1, R2, and R3).

Table 1. Significance of treatment effects for 1,041 fungal and 1,063 plant genes, as estimated by the mixed-model analysis of variance

\begin{tabular}{|c|c|c|c|c|c|c|}
\hline \multirow[b]{3}{*}{ Effects $^{b}$} & \multicolumn{6}{|c|}{ Significance level $^{\mathrm{a}}$} \\
\hline & \multicolumn{3}{|c|}{ Fungal genes } & \multicolumn{3}{|c|}{ Plant genes } \\
\hline & 0.05 & 0.01 & 0.001 & 0.05 & 0.01 & 0.001 \\
\hline Time & 43 & 30 & 23 & 51 & 39 & 28 \\
\hline Tissue & 45 & 27 & 21 & 19 & 10 & 4 \\
\hline Time $\times$ tissue & 388 & 316 & 224 & 302 & 242 & 163 \\
\hline Dye & 14 & 8 & 4 & 15 & 4 & 3 \\
\hline
\end{tabular}

${ }^{\text {a }}$ The number of reporters showing a $P$ value of less than the indicated level. Analyses were made on 1,041 fungal and 1,063 plant genes, at five different timepoints (time) and in two different conditions (tissue). At $P<0.05$, we calculated an experiment-wise significance value (Bonferroni value) of $4.8 \times 10^{-6}$ $\left(-\log _{10}=5.3\right)$, at $P<0.01$ of $9.5 \times 10^{-7}\left(-\log _{10}=6.0\right)$, and at $P<0.001$ of $9.5 \times 10^{-8}\left(-\log _{10}=7.0\right)$.

${ }^{\mathrm{b}}$ Gene effects due to the time component, which contains five different timepoints ( 2 to 21 days), the tissue component (ectomycorrhizal and reference tissue), and the combined effect of their interaction. The dye effect results from swapping the dye between hybridization extracts and is due to a nonstoichiometric incorporation of the two dyes in the labeling procedure. 
ing effects due to harvesting of biological material containing various compartments of ECM tissue, the present study provides several novel details on gene regulation associated with the physiological and morphological changes accompanying the development of the mantle and Hartig net. Some of these findings will be discussed below.

\section{Regulation of plant defense responses.}

There have been several reports suggesting that mycorrhizal fungi, particularly the arbuscular mycorrhizal fungi, can induce stress responses in plants similar to those induced by fungi pathogenic to plants (Garcia-Garrido and Ocampo 2002). Notably, a number of the transcripts that are differentially expressed in $B$. pendula during development of the symbiotic tissue display sequence similarities to genes that have been implicated to have roles in plant pathogen defense reactions including the generation of reactive oxygen species (ROS), the hypersensitive response (HR), the production of so-called pathogenesis related (PR) proteins, and antimicrobial compounds such as phytoalexins (Heil and Bostock 2002; Kombrink and Schmelzer 2001; Lamb and Dixon 1997). The majority of these transcripts were upregulated relative to the expression levels in the noninfected roots during the development of the mantle and Hartig net (4 and 8 days), and they were thus found in clusters A, B, and C (Fig. 5). At later stages, however, these responses were repressed in many cases and were comparable to levels detected under axenic conditions. Accordingly, we have previously found that only a few plant genes related to stress and defense responses are differentially regulated at an even later stage of ECM tissue development (25 days after contact) (Johansson et al. 2004).

Generation of ROS is an early response in plants towards pathogens and might lead to cell death and lesions (Kombrink and Schmelzer 2001). A number of scavengers are produced to restrict and chemically reduce active oxygen species and to block oxidant-mediated programmed cell death. One such scavenger, although not only induced in plant defense but also by auxin, is glutathione $S$-transferase (GST), and GST expression has been shown during the ECM association between E. globulus and Pisolithus microcarpus (Tagu et al. 2003). We detected a Glycine max GST homolog (T143C01959) that is differentially upregulated during mantle and Hartig net formation (Fig. 5, cluster C). A HR gene, the harpin induced gene (hin), has been seen to be transcribed in response to several bacterial pathogens (Gopalan et al. 1996). More recently, hinl transcription has been observed in several plants after challenge with fungal pathogens, such as in Oryzae sativa as a response to the rice blast fungus Mangnaporthe grisea (Kim et al. 2000) and in potato in response to the oomycete plant pathogen Phytophthora infestans (Tian et al. 2003). We found a homolog (T143A01910) for the Nicotiana tabacum hinl gene expressed in a pattern similar to that of the GST homolog (Fig. 5, cluster B). A strikingly similar expression pattern was found for a HR-induced protein during the ECM development in the E. globulus-Pisolithus microcarpus association (Duplessis et al. 2005).

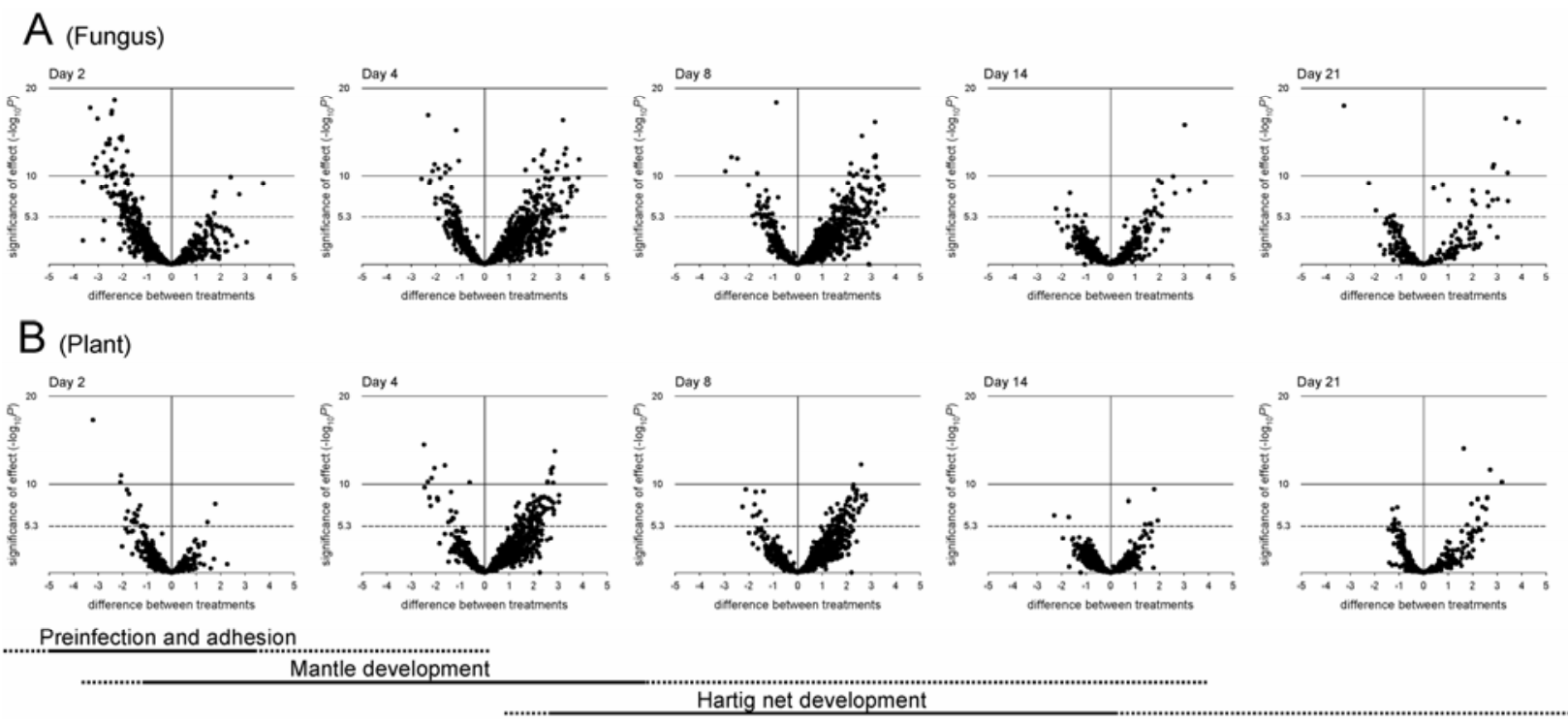

Fig. 3. Volcano plots of significance of ectomycorrhizal (ECM) versus reference effect at each timepoint $(2,4,8,14$, and 21 days). Each circle represents one of $\mathbf{A}, 1,041$ fungal and $\mathbf{B}, 1,063$ plant genes, with the $-\log _{10}$ of the $P$ value from the gene model plotted against the difference between least-square means for the ECM versus reference effect. Horizontal dashed line represents the test-wise Bonferroni threshold (a combination of $P<0.05$; approx. 1,100 fungal or plant genes, respectively; five different timepoints; two different conditions). A difference of one residual unit represents a twofold change, because raw fluorescence intensities are $\log _{2}$-transformed. Effects are simply the difference in least-square means from the gene-specific mixed models.

Table 2. Genes significantly differentially regulated in ectomycorrhizal tissue as compared with the reference tissue at each timepoint, as estimated by the mixed-model analysis of variance

\begin{tabular}{|c|c|c|c|c|c|c|}
\hline \multirow[b]{2}{*}{ Day } & \multicolumn{3}{|c|}{ Fungus } & \multicolumn{3}{|c|}{ Plant } \\
\hline & Total $^{\mathrm{a}}$ & Upregulated & Downregulated & Total & Upregulated & Downregulated \\
\hline 2 & 112 & 7 & 105 & 17 & 2 & 15 \\
\hline 4 & 128 & 88 & 40 & 93 & 75 & 18 \\
\hline 8 & 122 & 96 & 26 & 64 & 55 & 9 \\
\hline 14 & 25 & 19 & 6 & 8 & 6 & 2 \\
\hline 21 & 23 & 20 & 3 & 21 & 13 & 8 \\
\hline Nonredundant set ${ }^{\mathrm{b}}$ & 251 & $\ldots$ & $\ldots$ & 138 & $\ldots$ & $\ldots$ \\
\hline
\end{tabular}

a The number of genes at $P<0.05$ and with the Bonferroni-corrected experiment-wise significance value set at $4.8 \times 10^{-6}\left(-\log _{10}=5.3\right)$.

${ }^{\mathrm{b}}$ From collecting significant genes obtained at each timepoint followed by filtering for a nonredundant set. 
GRAS proteins, a recently discovered family of plant-specific proteins, have been suggested to play one or more key roles as transcriptional regulators in the early stages of defense signaling following fungal perception and pathogenesis (Day et al. 2003). We observed that a B. pendula GRAS homolog (T143C02271) became highly upregulated at 2 and 4 days after contact (Fig. 5, cluster C). This gene product is highly ho- mologous to a GRAS protein (CIGR2) in O. sativa, which is strongly activated during challenge with rice blast fungus (Day et al. 2003). However, due to the fact that GRAS proteins can have important roles in a number of different processes, including meristem maintenance and development (Bolle 2004; Kamiya et al. 2003), we could also hypothesize that the GRAS gene homolog identified is involved in formation and

\section{Day}

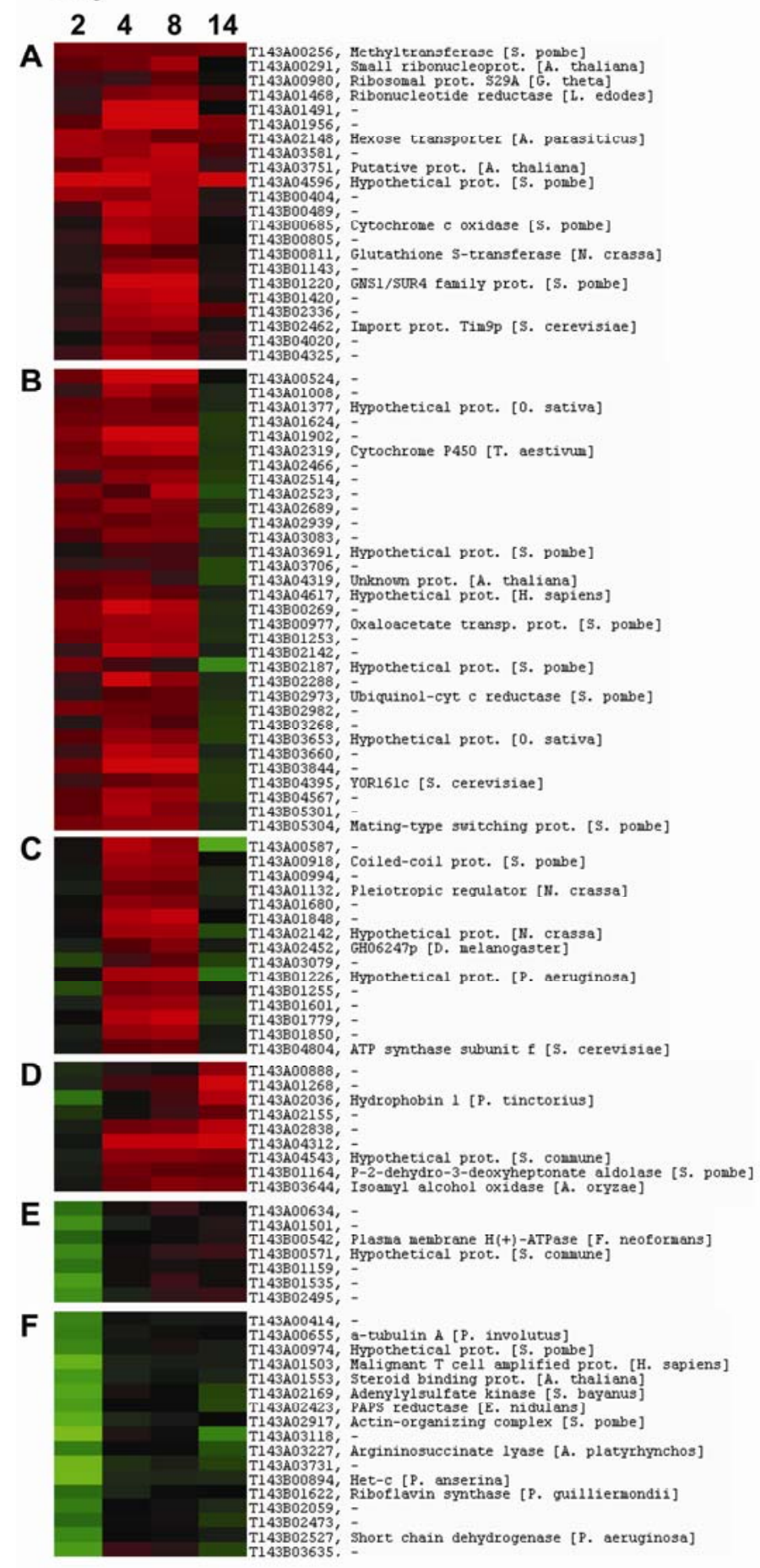

\section{Day}

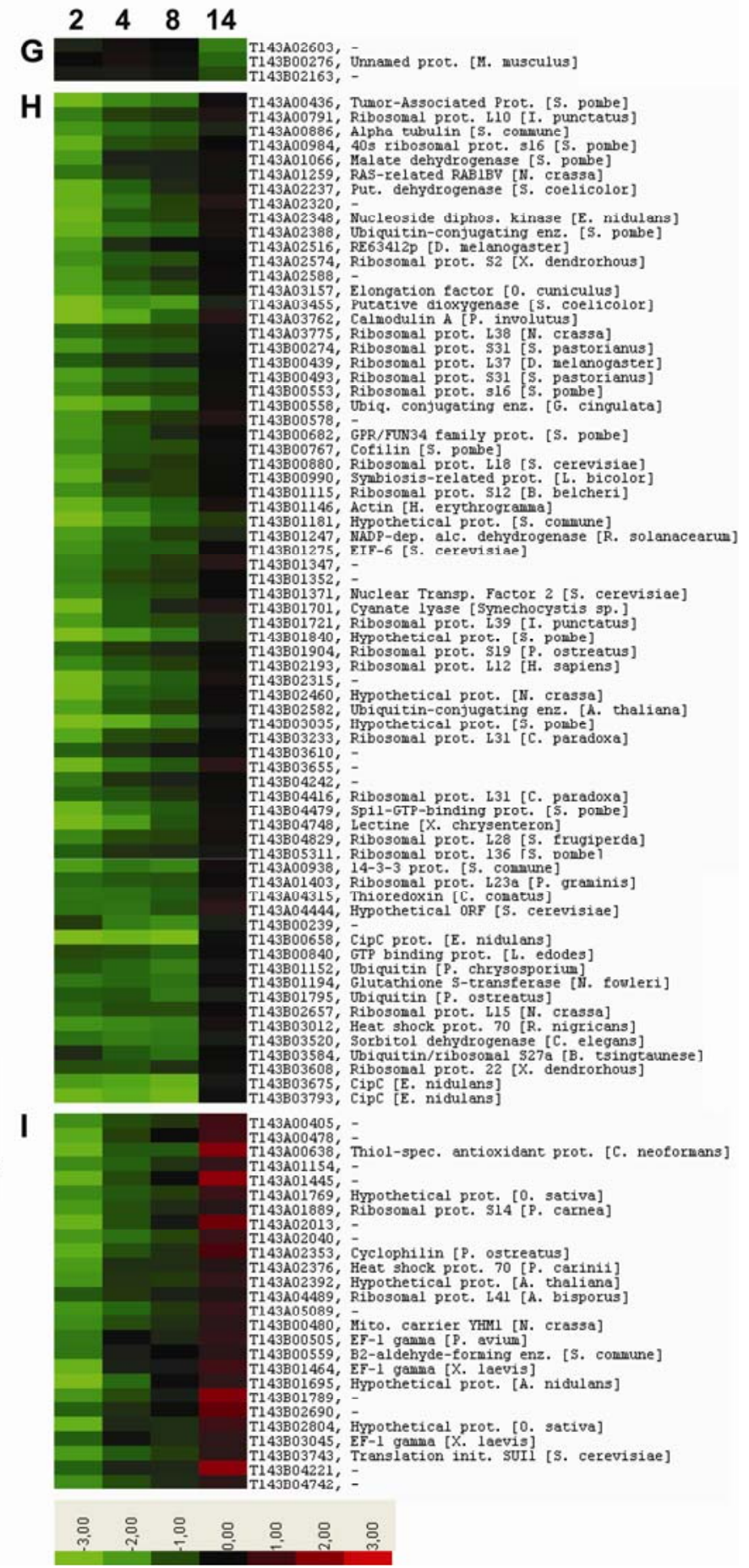

Fig. 4. The transcriptional profiles of 206 fungal genes (organized into nine clusters by k-means clustering [uncentered correlation and 2,000 runs]) showing significant differential regulation during ectomycorrhizal (ECM) development. Lanes represent 2, 4, 8, and 14 days after contact between symbionts. (day 21 data is omitted here due to missing data for a portion of reporters). Estimated difference in expression between ECM and reference tissue is shown as red for relative upregulation in ECM and green for relative downregulation (the scale indicates $\log _{2}$ differences). For each row, the clone identity is listed, together with the description for a putatively homologous gene. The nine clusters are defined as genes showing $\mathbf{A}$, general induction; $\mathbf{B}$, early and mid-induction, late repression; $\mathbf{C}$, early and late repression, mid-induction; $\mathbf{D}$, mid- and late induction; $\mathbf{E}$, early repression; $\mathbf{F}$, early and late repression; $\mathbf{G}$, late repression; $\mathbf{H}$, early and mid-repression; and $\mathbf{I}$, early and mid-repression, late induction. 
shortening of lateral roots, which is commonly associated with ECM formation.

At least 14 families of PR proteins have been identified (van Loon and van Strien 1999). Bet v 1, the major birch-pollen allergen, is a representative of the PR-10 protein family, whose members have been identified in more than 70 species of flowering plants, both mono- and dicotyledons. Although the allergenic properties of PR-10 proteins have been studied extensively, their biological function in plants is not known (Markovic-Housley et al. 2003). Among B. pendula genes, we

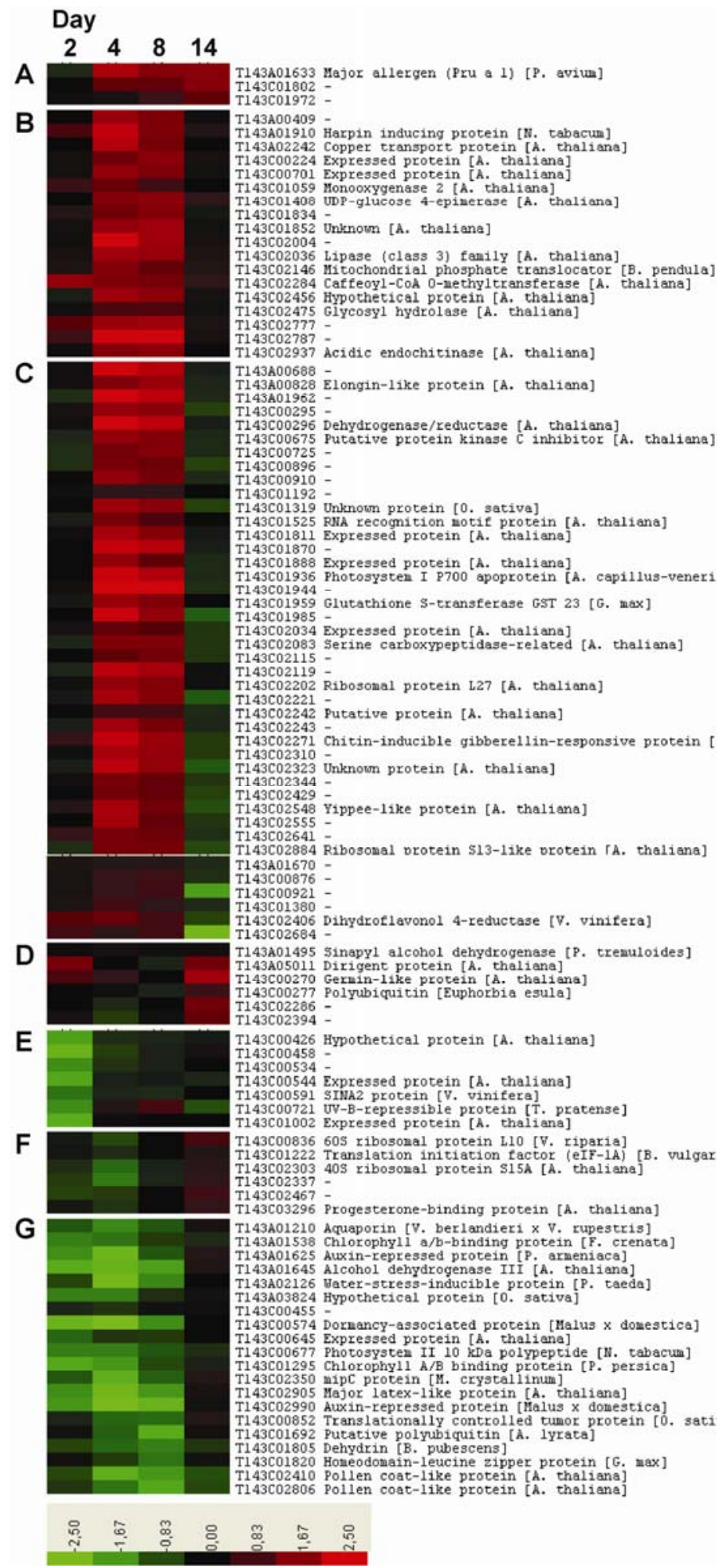

Fig. 5. The transcriptional profiles of 102 plant genes (organized into seven clusters by k-means clustering [uncentered correlation and 2,000 runs]) showing significant differential regulation during ectomycorrhizal (ECM) development. Lanes represent 2, 4, 8, and 14 days after contact between symbionts. (day 21 data is omitted here due to missing data for a portion of reporters). Estimated difference in expression between ECM and reference tissue is shown as red for relative upregulation in ECM and green for relative downregulation (the scale indicates $\log _{2}$ differences). For each row, the clone identity is listed together with the description for a putatively homologous gene. The seven clusters are defined as genes showing $\mathbf{A}$, general induction; $\mathbf{B}$, mid-induction; $\mathbf{C}$, midinduction, late repression; D, early and late induction; E, early repression; F, early repression, late induction; and $\mathbf{G}$, early and mid-repression. 
found two different Bet v 1 homologs that were differently and differentially regulated during ECM formation, and one of these, a Prunus avium homolog (T143A01633), was highly upregulated after 4 days of contact (Fig. 5, cluster A). A markedly similar expression profile was observed for a Bet $\mathrm{v} 1$ homolog in the E. globulus-Pisolithus microcarpus association (Duplessis et al. 2005). The second homolog, an Arabidopsis thaliana homolog (T143C02905), showed a different pattern and appeared to be significantly downregulated in the early and midstages but, at a later stage, upregulated after 14 days of contact (Fig. 5, cluster G). This Bet v 1 homolog (T143C02905) has previously been observed to be significantly upregulated during an even later stage of ECM development (Johansson et al. 2004).
Plant chitinases belong to another family of PR proteins that catalyze the hydrolysis of chitins, common components of the fungal cell wall, and play important roles in plant defense against fungal pathogens (Collinge et al. 1993). An A. thaliana acidic endochitinase homolog (T143C02937) was found to be highly expressed during mantle and Hartig net formation (Fig. 5 , cluster B). Further local responses in surrounding cells include changes in the composition of the plant cell wall that inhibit penetration by pathogens, such as amplified cell-wall lignification. Increased expression of caffeoyl-CoA $O$-methyltransferase (CCoAOMT), an enzyme involved in phenylpropanoid pathways and lignin biosynthesis, has been observed in relation to pathogenic challenge in Vitis vinifera (Busam et al. 1997). The activation causes a short-term accumulation of phe-

Table 3. Quantitative polymerase chain reaction targets, primers, and expected amplicons

\begin{tabular}{|c|c|c|c|c|}
\hline \multirow[b]{2}{*}{ Target } & \multirow[b]{2}{*}{ Accession $^{a}$} & \multicolumn{2}{|c|}{ Size (bp) } & \multirow[b]{2}{*}{ Primers } \\
\hline & & cDNA & gDNA & \\
\hline \multirow[t]{2}{*}{ hetCl } & AY585933 & 167 & 258 & P453 (5'-CTTCTCCGCGGTCTCTCGTT) \\
\hline & AY585988 & & & P454 (5'-TGTGGGCATGCTTTCATCG) \\
\hline \multirow[t]{2}{*}{$n d k A$} & AY585937 & 173 & 230 & P459 (5'-ATGATCAAGTACATGCAAAGTGGC) \\
\hline & AY585965 & & & P460 (5'-TCGGAACCGTGGCAGATATTAC) \\
\hline \multirow{2}{*}{ micA } & AY585936 & 170 & 226 & P457 (5'-CAACGCCCCTGGTTCATTC) \\
\hline & AY585970 & & & P458 (5'-GCGTCTTCACCGTGTCGAGT) \\
\hline \multirow[t]{2}{*}{$h x t A$} & AY585934 & 178 & 230 & P455 (5'-GTTTCAACATCTTCAGCTTTGTCATC) \\
\hline & AY585978 & & & P456 (5'-TCTTCCAGAGTTCGGTTCTTGGT) \\
\hline \multirow[t]{2}{*}{ calA } & AY585925 & 151 & 218 & P447 (5'-GCGACACGGACAGTGAAGAAG) \\
\hline & AY586017 & & & P448 (5'-TCGCGGATCATCTCGTCAA) \\
\hline
\end{tabular}

${ }^{a}$ Accession numbers for fully characterized cDNA and genomic DNA, respectively (Le Quéré et al. 2004).
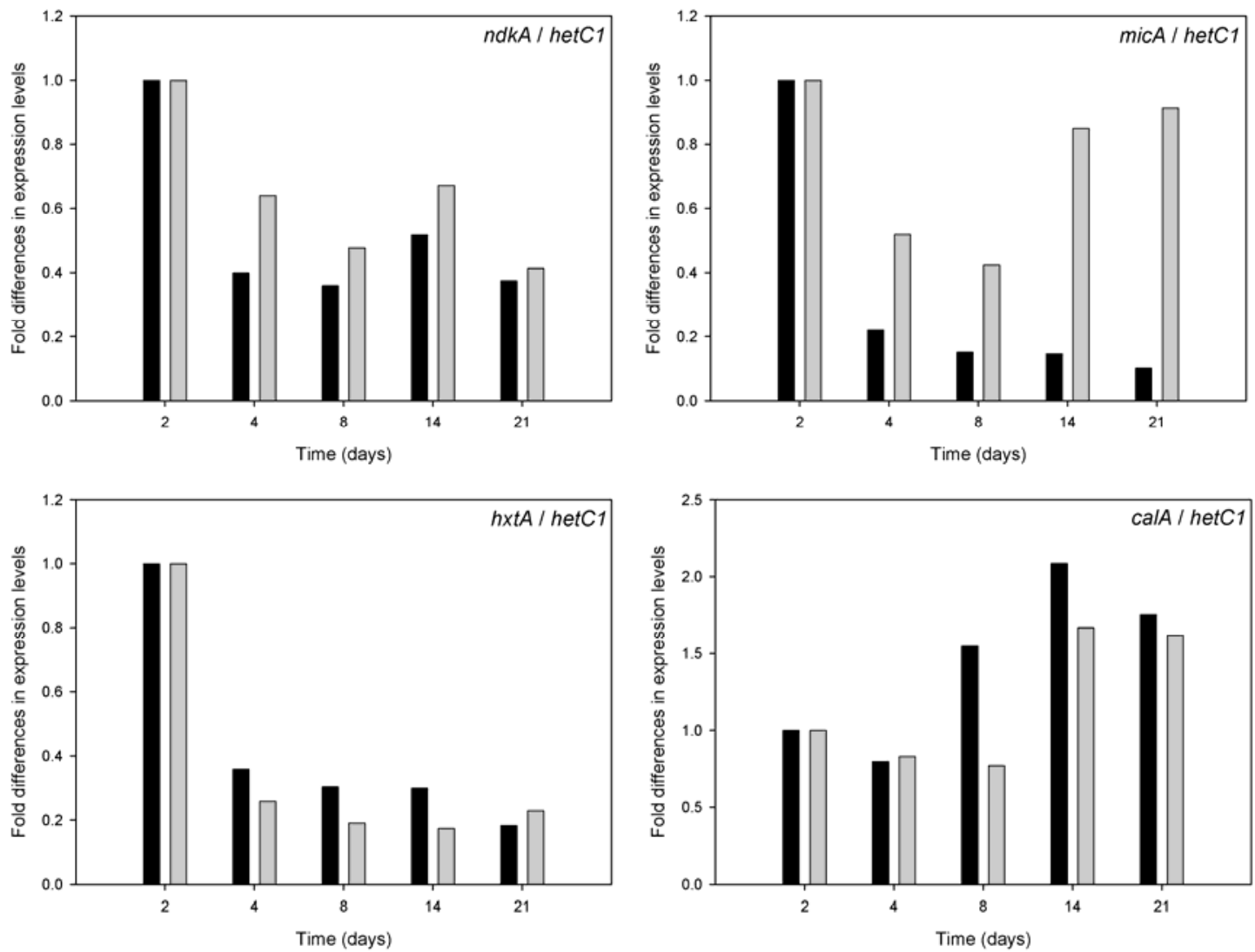

Fig. 6. Fold differences between target genes and a normalizer gene, as obtained from relative quantitative real-time polymerase chain reaction (black bars) and cDNA microarray (gray bars) analyses. The genes tested were ndkA, micA, hxtA, and calA, together with hetC1, which was used as normalizer (target/normalizer in the upper right corner of each panel). Triplicate measures (Ct values) for each template (ectomycorrhizal tissue for three biological replicates at five different timepoints) and each target were averaged, followed by averaging of data for all three biological replicates. Fold differences in expression levels were then calculated for the target and the normalizer genes for the five different timepoints. For scaling purposes, the fold-difference value at 2 days has been used as calibrator. 
nolic metabolites, which, by themselves, may possess potent antimycotic activity as such, or they may protect the cells indirectly after incorporation into the cell wall. An A. thaliana CCoAOMT homolog (T143C02284) was highly expressed after 2 days of contact, and it remained highly expressed up to 14 days after contact (Fig. 5, cluster B).

A few other stress-related plant genes displayed a different pattern of regulation. These genes were upregulated during the stages of fungal-plant contact and initial mantle formation (2 days), then downregulated during the stages involving maturation of the mantle and development of the Hartig net (4 and 8 days), and then upregulated in the developed symbiotic tissue (14 days) (Fig. 5, cluster D). Among them was an A. thaliana dirigent protein homolog (T143A05011). The plant diseaseresistance response protein or dirigent protein was initially characterized in Pisum sativum (Culley et al. 1995) and showed a rapid accumulation in response to pathogenic challenge. More recently, this protein has been shown to be essential for initiation of and phenoxy radical coupling during lignin biosynthesis (Davin and Lewis 2000). Another gene (T143A01495), encoding a Populus tremuloides sinapyl alcohol dehydrogenase homolog, showed a similar pattern of regulation. This enzyme is involved in the last step of lignin biosynthesis (Li et al. 2001). Germins and germin-like proteins (GLP) constitute a large and highly diverse family of ubiquitous plant proteins. A number of cellular functions for GLP have been suggested, and among these are roles as structural proteins and as a defense against pathogens, as GLP are glycoproteins that are somehow associated with the extracellular matrix (Bernier and Berna 2001). A recently characterized GLP in Medicago truncatula (Doll et al. 2003) showed strong induction in roots and root cultures colonized by the endomycorrhizal fungus Glomus intraradices. In our system, we detected an A. thaliana GLP homolog (T143C00270) differentially regulated during early (2 and 4 days) and late stages (14 days) (Fig. 5, cluster D).

\section{Regulation of plant genes associated with tolerance to water stress.}

A number of plant genes that were expressed at lower levels in the infected roots, as compared with the noninfected reference tissue, during the development of the mantle and Hartig net (Fig. 5, cluster G), displayed sequence similarities to genes known to be regulated during water stress in plants. One of these was a Betula pubescens dehydrin (dhn2) (Welling et al. 2004) homolog (T143C01805). Dehydrins form a group of proteins that accumulate in plant tissues under conditions that provoke increased desiccation tolerance, such as high salinity, water deficit, and low temperature and in response to abscisic acid (ABA). They have been implicated to be key components of dehydration tolerance (Robertson 2003). Like several other genes encoding proteins supposed to have a function related to protection against water stress, the apparent downregulation in the early and midstages of ECM development was due to a higher level of expression in the reference tissue as compared with the infected tissue (Fig. 7). During a later stage of infection (14 days), the expression levels of these genes in the reference tissue decreased. These data suggest that the formation of

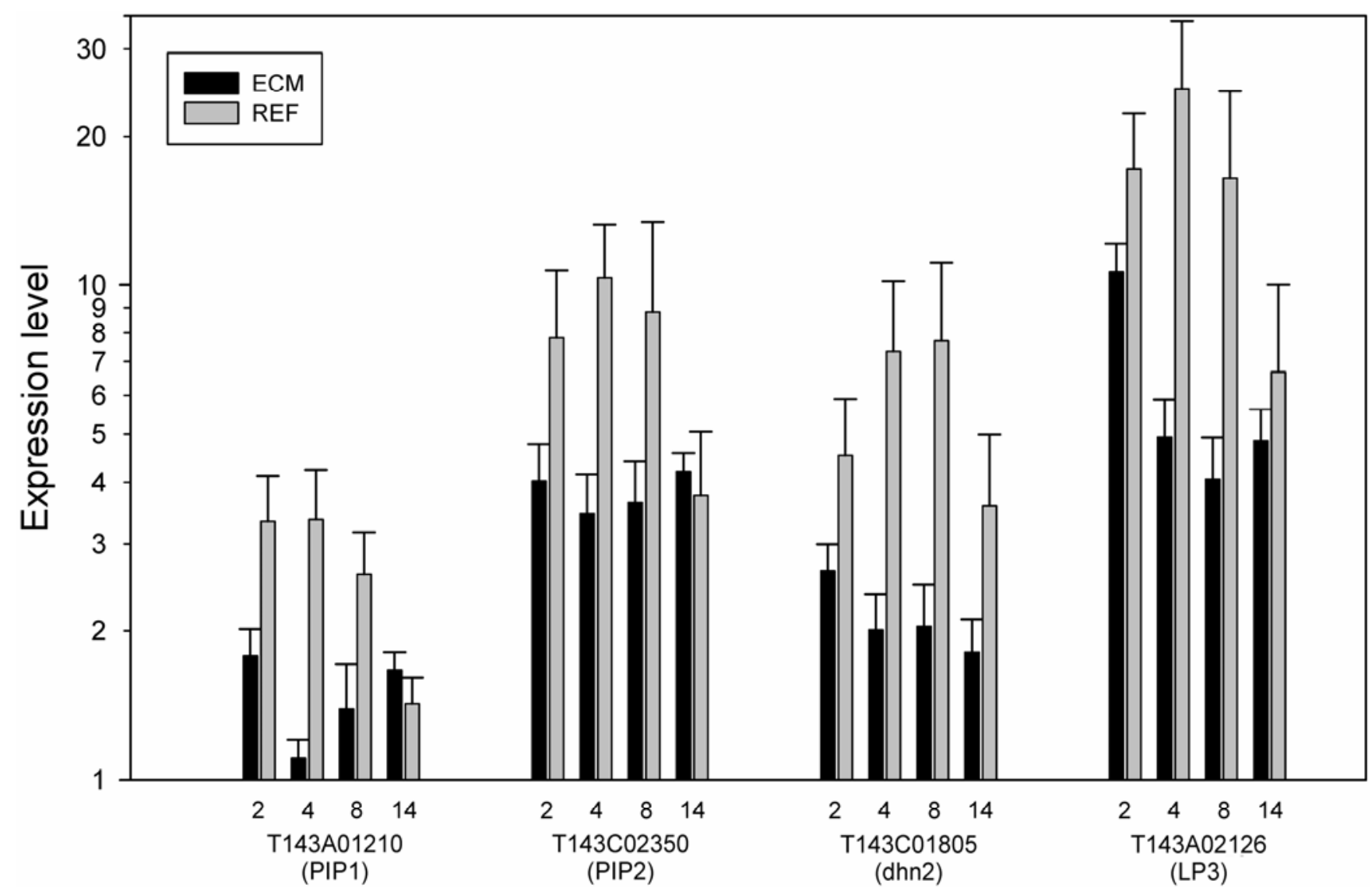

Fig. 7. A histogram showing normalized gene expression levels for four Betula pendula genes putatively related to water potential and water stress. The residuals from the normalization model are plotted for each gene at four different timepoints (2, 4, 8, and 14 days) and during ectomycorrhizal (ECM) or axenic conditions (REF). The standard error for each measurement is indicated. The expression levels shown are for two different plasma membrane major intrinsic proteins, a Vitis berlandieri $\times$ Vitis rupestris putative aquaporin (PIP1) homolog (T143A01210) and a Mesembryanthemum crystallinum mipC protein (PIP2) homolog (T143C02350), as well as for a Betula pubescens dehydrin (dhn2) homolog (T143C01805) and a Pinus taeda water-stress-inducible protein (LP3) homolog (T143A02126). 
the fungal mantle protects the roots from the water stress encountered by the noninfected roots of young plant seedlings. Although this could potentially be an artifact introduced by the laboratory system used, there are indications on long-term improvements by ECM-forming fungi of drought resistance in ECM plants (Davies et al. 1996; Shi et al. 2002; Smith and Read 1997). The ABA and water-deficit stress (WDS)-induced proteins represent a family of plant proteins induced by WDS or ABA stress and ripening. The role of these proteins at the molecular level is unclear, but they have been observed to be upregulated in a number of plant species as a consequence of WDS (Padmanabhan et al. 1997). A Pinus taeda homolog (T143A02126) showed coregulation with the putative dehydrin homolog (T143C01805) (Fig. 7).

Two genes with sequences homologous to members of the water channel proteins, major intrinsic proteins (MIP) (syn. aquaporins) were also regulated in a similar manner. MIP are thought to be important in mediating the water permeability of root cells in response to various stimuli, such as day-night cycles, nutrient deficiency, or stress (Javot and Maurel 2002). The regulated MIP of $B$. pendula belong to the subgroup of plasma membrane intrinsic proteins (PIP) (Schäffner 1998) and include a PIP1 (T143A01210) and a PIP2 (T143C02350) homolog (Fig. 7).

\section{Regulation of fungal carbon metabolism.}

ECM symbiosis causes a severe carbohydrate drain, and up to $30 \%$ of total photoassimilate production can be transferred to the fungal partner (Finlay and Söderström 1992). Sucrose, which is the preferred transport sugar in most plants, is not commonly assimilated by the ECM fungi investigated to date. Rather, it is assumed that sucrose is delivered into the apoplast, hydrolyzed via a plant-derived acid invertase, and then, assimilated by the fungus (Schaeffer et al. 1995). For the fungus to form a strong sink for carbohydrates, hexoses must be transferred efficiently over the plasma membrane and, then, quickly incorporated into fungal metabolite pools. So far, the molecular characterization of hexose transporters in ECM fungi has been limited to the AmMst1 gene from Amanita muscaria (Nehls et al. 1998), which has been shown to be upregulated during ECM associations (Nehls et al. 1998, 2001). We characterized a transcript (T143A02148) encoding a putative hexose transporter that is significantly upregulated during the entire course of ECM development (Fig. 4, cluster A). The corresponding cDNA clone was entirely sequenced ( $h x t A$ (AY585934)) and is predicted to encode a 523-aa residue protein with relatively high sequence similarity to MFS protein members (Pfam PF00083; E-value 1.9e-94) and to the Aspergillus parasiticus hxtA-encoded hexose transporter in particular (39\% identity). A hydropathy analysis clearly predicted 12 transmembrane domains, which is a characteristic of this family of integral membrane proteins. Although distantly related to the A. muscaria hexose transporter, we propose that this putative hexose transporter is a candidate for fungal hexose assimilation in the association of Paxillus involutus with $B$. pendula.

Homologues for several key enzymes involved in the mitochondrial respiratory chain were observed to be highly upregulated during the entire timecourse. One of those were a Schizosaccharomyces pombe ubiquinol-cytochrome $\mathrm{C}$ reductase 14-kDa subunit homolog (T143B02973) that is part of the second of three proton pumps in the respiratory chain, the Qcytochrome c oxidoreductase (also known as Complex III and cytochrome reductase). This subunit, part of a multienzyme complex, is not directly involved in electron transfer but has a role in assembly of the complex. In coregulation, we found a Schizosaccharomyces pombe cytochrome c oxidase VIb sub- unit homolog (T143B00685), which is part of the third and last proton pump of the electron-transport chain. In this complex, the reduced cytochrome c, generated by Complex III, is oxidized with a coupled reduction of $\mathrm{O}_{2}$ into two molecules of $\mathrm{H}_{2} \mathrm{O}$. Concomitant with flow of electrons through the respiratory chain, a proton-motive force is generated that is used by the ATP synthase complex for synthesis of ATP. In our system, a Saccharomyces cerevisiae ATP synthase subunit f homolog (T143B04804), part of the mitochondrial ATP synthase (Devenish et al. 2000), were found to be coregulated with the components of the respiratory chain mentioned above. Furthermore, a Saccharomyces cerevisiae Tim9p homolog (T143B02462) appeared to be coregulated with these proteins. The soluble Tim9p-Tim10p (Tim, translocase of inner membrane) complex of the mitochondrial intermembrane space mediates the import of the carrier proteins and is a component of the TIM22 import system. The Tim9p-Tim10p complex bind specifically to the transmembrane domains of the ADP/ATP carrier (Curran et al. 2002). From these observations, we suggest that the mitochondrial respiratory chain together with ATP synthase is highly upregulated during ECM formation and especially during mantle and Hartig net formation. Structural analyses of the Hartig net compartment have revealed a high number of mitochondria present in the highly branched hyphae encircling the epidermal plant cells (Massicotte et al. 1987; Smith and Read 1997). This upregulation in respiration could be connected to an activated carbohydrate metabolism through the citric acid cycle (TCA cycle). However, a homolog (T143A01066) for a key enzyme in the TCA cycle, the mitochondrial malate dehydrogenase, was clearly downregulated during mantle and Hartig net formation, which made us hypothesize that the increase in expression of fungal genes related to respiration was due to an upregulation in fatty acid biosynthesis in response to an elevated influx of plant hexoses. Unfortunately, significant upregulation of components within the pathway of fatty acid biosynthesis could not be confirmed among the gene reporters currently available. The differential regulation of components in the respiratory chain and the TCA cycle during mantle and Hartig net formation were transient events and were different from what we observed in a previous study on functional ECM (Johansson et al. 2004) in a later stage of development (25 days of contact). In that study, we observed upregulation of a hexokinase, part of a glucose signaling system, and downregulation of components in lipid $\beta$ oxidation. From those observations, we suggested that the fungal carbon metabolism were directed by glucose repression, which might be expected when the fungal assimilation of glucose is firmly established (Johansson et al. 2004).

\section{Regulation of fungal morphology.}

Of the 206 fungal genes undergoing significant regulation, 70 genes were clustered into one group, based upon being repressed during mantle and Hartig net formation (Fig. 4, cluster $\mathrm{H})$. For 50 of these, homologous sequence information was available. Prominent within this group was a suite of genes involved in protein synthesis. All were highly repressed during the early stages of ECM formation, were derepressed during later stages, and were even upregulated by day 21 . Also, within this cluster, there were a number of genes involved in signal transduction pathways, posttranslational modification, protein trafficking and turnover, and the reorganization of cell structure, such as components of the cytoskeleton assembly machinery.

In the saprotrophic mode, growth of ECM-forming fungi (as with other filamentous fungi) occurs by the polar extension of hyphae. Upon contact with plant roots, however, radial hyphal growth is curtailed and replaced by increased branched hyphal development during mantle and Hartig net formation (Horan et 
al. 1988; Nylund and Unestam 1982; Timonen et al. 1993). Microfilaments of actin are central to the reorganization of cell structure during morphogenesis; their interaction with actinbinding and other associated proteins composes and controls the actin cytoskeleton. In yeast, extracellular and intracellular signals are transduced by the Rho-GTPase Cdc42 module that signals the polarisome and Arp2/3 complexes to direct localized assembly of actin filaments at polarization sites. The Arp2/3 complex is composed of seven subunits, and it regulates the formation of branched actin filaments that form a fine network typically underlying the cell surface. Actin patches and filaments have been observed at sites of polarization, where they are presumed to direct localized myosin-driven vesicle transport to the growth site (dos Remedios et al. 2003; Harris and Momany 2004). In this study, we observed an actin gene homolog (T143B01146-actA [AY585923]) and a homolog of P21-Arc (T143A02917), a 21-kDa subunit of the Arp2/3 complex, to be coregulated in response to ECM colonization. Both genes were strongly downregulated on day 2 after contact. During mantle and Hartig net development, expression of both genes was still repressed but less so in the case of the Arp2/3 complex subunit. By day 21, when fully developed ECM root tips had formed, expression of the Arp2/3 subunit was upregulated. Transcriptional analysis on the Suillus bovines actin (Gorfer et al. 2001) showed no difference in expression between vegetative and ECM tissue at different stages of development. However, during the development of the E. globulus-Pisolithus microcarpus association actin repression was detected in a similar pattern as observed here (Duplessis et al. 2005). In all cases, it should be remembered that up- or downregulation is a relative term derived from the comparison to the expression in free-living saprotrophic fungal mycelium of the same age. Rapid radial extension of hyphae of free-living mycelium occurred at all timepoints, but polarized hyphal growth is usually slowed or curtailed upon contact between the mycelial front and the roots of birch seedlings. In its place, branched hyphal development usually occurs during mantle and Hartig net formation. Downregulation of components of the actin cytoskeletal machinery during the development of mantle and Hartig net tissue was unexpected, since the highly branched hyphal structures might be expected to require continuous rearrangements of the actin cytoskeleton. We suggest that this apparent downregulation results from the comparison with fungal mycelium, in which rapid radial hyphal extension is maintained. We suppose that the actin cytoskeleton is intimately involved in the morphogenesis of ECM root-tip tissues, but that the level of gene expression required to complete these developmental changes may be lower than that required to maintain radial hyphal growth. The downregulation of the P21-Arc subunit of the Arp2/3 complex, involved in branch formation control in the actin cytoskeleton, was much more transient than that of actin itself, which may indicate that a different relationship exists between actin and the Arp2/3 complex during ECM tissue formation than during radial hyphal extension. In the ECM-forming fungus Suillus bovines, both the Rho-GTPase Cdc42p and actin were localized to the tips of vegetative hyphae, as well as in the plasma membrane of swollen hyphal tips typically present during the formation of the symbiotic state (Gorfer et al. 2001).

Furthermore, a gene homologous (T143B00767) to that of the actin depolymerizing protein cofilin displayed a pattern of regulation similar to that of both actin and P21-Arc. Cofilin is an essential protein that has actin-severing activity and that allows rapid recycling of actin monomers. Again, this gene appears to be downregulated during early ECM formation, probably for the same reasons as discussed above in relation to actin cytoskeletal components. Interestingly, 14-3-3 proteins have been shown to interact with cofilin to mediate changes in the actin cytoskeleton (Birkenfeld et al. 2003), and a Schizophyllum commune 14-3-3 protein homolog (T143A00938) showed coregulation early during ECM tissue formation.

\section{Concluding remarks.}

The establishment of an ECM symbiosis encompasses a series of morphological and developmental processes of both the colonizing mycelium and the tree lateral roots. In this investigation, we have characterized $B$. pendula and Paxillus involutus transcript patterns in association with initial colonization, mantel and Hartig development, and maturation into functional ECM. In a rather similar study recently published on the E. globules-Pisolithus microcarpus association (Duplessis et al. 2005), we found, on a global level, remarkable similarities in expression and functional profiles between the two systems during the course of ECM development and, particularly, in the plant response. In both systems, there is coincident with mantle and Hartig net formation an upregulation of components involved in fungal carbon metabolism. In our system, we found upregulation and coregulation among a number of genes putatively involved in mitochondrial respiration. Another transcriptional pattern in both systems was an early repression of fungal genes encoding components of the cytoskeleton assembly machinery.

A clear and evident plant response in both systems is an upregulation of a number of genes involved in stress and defense programs. This response is early (mantle and Hartig net formation), transient, and hardly detectable at later stages and indicates that colonization and mantle and early Hartig net formation elicit a plant defense program similar to what can be seen during pathogenic interactions. Another feature of both systems during ECM formation is a strong repression of plant genes normally involved in water stress. In our system, several components showed coregulation and indicates a plant water stress relief due to ECM formation. Only from this brief comparison, there are several indications of a general molecular scheme involved in the development of ECM associations, and further comparative analyses of fungal and plant candidate genes and their transcriptional patterns will certainly reveal general details.

\section{MATERIALS AND METHODS}

\section{Biological material, media, and culture conditions.}

Paxillus involutus (Batsch: Fr.) Fr. (ATCC 200175) was maintained on MMN agar medium containing glucose $(2.5 \mathrm{~g}$ per liter) (Brun et al. 1995). Dry seeds of Betula pendula (Skuleskogen, SkogForsk, Sweden) were stored at $-20^{\circ} \mathrm{C}$ until used. A system for the formation of ECM between $B$. pendula and Paxillus involutus has been described previously (Brun et al. 1995) and was used here. Axenic cultures of Paxillus involutus and $B$. pendula were grown in parallel under identical conditions, to be used as reference tissue. The plant, the fungus, and ECM syntheses were grown under controlled conditions consisting of $22^{\circ} \mathrm{C}$ day and $15^{\circ} \mathrm{C}$ night temperatures, a 16-h light $\left(70 \mu \mathrm{mol} \mathrm{m} \mathrm{m}^{-2} \mathrm{~s}^{-1}\right)$ and 8 -h dark cycle, and $80 \%$ relative humidity. The colonization and development was monitored microscopically, and the material was harvested at five timepoints $(2,4,8,14$, and 21 days) during the course of ECM development (Fig. 1).

\section{Microscopic investigations.}

In parallel with the timecourse experiment, ECM root tips were collected and prepared for light microscopy. Briefly, the samples were fixed for $3 \mathrm{~h}$ at room temperature in a solution 
containing $3.7 \%$ (vol/vol) formaldehyde, $50 \%$ (vol/vol) ethanol, and 5\% (vol/vol) glacial acetic acid. After fixation, the tissue was embedded in $10 \%$ (wt/vol) gelatin, $2 \%$ (vol/vol) glycerol, and $0.8 \%$ (vol/vol) dimethyl sulfoxide (DMSO), frozen on a Microm HM440E microtome (Carl Zeiss AB, Stockholm, Sweden) from which transverse sections of 50 to $60 \mu \mathrm{m}$ thickness were cut. Sections were submerged in water $\left(50^{\circ} \mathrm{C}\right)$ to remove gelatin, were stained with chlorazol black (Brundrett et al. 1984), and then, were examined under a light microscope.

\section{Total RNA preparation and aRNA synthesis.}

At harvesting, always $11 \mathrm{~h}$ into the photoperiod, ECM (colonized primary root axis), plant (primary root axis), or fungal tissue (mycelial radial front) was snap-frozen in liquid nitrogen and was ground in a precooled mortar with a pestle. Total RNA was isolated from approximately $100 \mathrm{mg}$ of sample using a hot phenol extraction method (Bugos et al. 1995). Total RNA was further purified, using the RNeasy plant mini kit (Qiagen $\mathrm{GmbH}$, Hilden, Germany) according to the manufacturer's instructions. Total RNA was finally eluted in $60 \mu \mathrm{l}$ of $\mathrm{H}_{2} \mathrm{O}$ and was stored at $-80^{\circ} \mathrm{C}$ until use. For the preparation of the reference tissue sample, equal amounts of fungal and plant RNA for each timepoint were mixed, referred to as "reference tissue" in the text. Antisense RNA (aRNA) was synthesized in one round of T7-based linear mRNA amplification (Wang et al. 2000) but by using a slightly modified protocol according to M. Diehn (Stanford University, CA, U.S.A.). Preparations of both total RNA and aRNA were inspected by gel electrophoresis and titers were determined spectrophotometrically.

\section{cDNA microarray, labeling, and hybridization analysis.}

Based on a previously described collection of full-length cDNAs (Johansson et al. 2004), a microarray was designed and slides were fabricated. The array design (Lund Univ Mycorrhiza_Betula pendula-Paxillus involutus $10 \mathrm{k}$, version 1.2 , accession number A-MEXP-92) is available from the EMBLEBI ArrayExpress database. A nonredundant set of 2,159 expressed sequence tags (EST), either of putatively fungal $(1,075)$ or plant $(1,074)$ origin were used as reporters. Among those printed, there were 10 EST reporters excluded from the analyses, due to uncertainty about putative origin. cDNA PCR products were printed on UltraGAPS coated slides (Corning Glass, Corning, NY, U.S.A.), using a 16-pin configured MicroGrid II array printer controlled by the MicroGrid TAS application suite (ver. 2.2.0.6) (BioRobotics, Genomic Solutions Ltd, Cambridgeshire, U.K.). The microarray was designed as two identical tool arrays, each containing 16 blocks (subarrays) and with each reporter replicated twice within each block, which provided on-chip quadruplicates for each reporter. Additionally, various positive and negative control reporters were replicated in various positions within each block, such as positive homologous controls, i.e., Paxillus involutus and B. pendula genes as well as negative heterologous controls, such as human reporters. Also printed were eight different heterologous reporters (ArrayControl, Ambion (Europe) Ltd, Cambridgeshire, U.K.), for which complementary RNAs were spiked into the amplification and labeling process of the hybridization extracts. Each control reporter was present in up to 64 per-chip replicates.

Microarray analyses were performed on three independent biological replicates (R1, R2, and R3) grown under identical conditions. For dual color labeling (Cy3 or Cy5), a total of 1 $\mu \mathrm{g}$ aRNA for each hybridization extract was used, including exogenous ArrayControl spikes (Ambion), using the CyScribe postlabeling kit (Amersham Biosciences, Uppsala, Sweden). After cDNA synthesis and labeling, hybridization extracts were finally purified using the QIAquick PCR purification kit
(Qiagen). After purification, the Cy3- and Cy5-labeled hybridization extracts were combined in an amber microfuge tube (Eppendorf AG, Hamburg, Germany) and, after evaporation, dissolved in $6 \mu \mathrm{l}$ of $\mathrm{H}_{2} \mathrm{O}$. After denaturation at $95^{\circ} \mathrm{C}$ for $2 \mathrm{~min}$ and a 30 -s incubation on ice, $1.5 \mu \mathrm{l}$ of $\mathrm{dT}_{80}(1 \mathrm{mg} / \mathrm{ml})$ was added, followed by incubation at $75^{\circ} \mathrm{C}$ for $45 \mathrm{~min}$. The cDNA was mixed with 7,5 $\mu \mathrm{l}$ of hybridization buffer (CyScribe postlabeling kit; Amersham Biosciences), and $15 \mu \mathrm{l}$ of formamide. The combined hybridization extract was applied onto the slide and was sealed under a LifterSlip coverslip (Eire Scientific Company, Portsmouth, NH, U.S.A.). Slides were placed in humidified CMT hybridization chambers (Corning) and were incubated in a hybridization oven at $42^{\circ} \mathrm{C}$ for $18 \mathrm{~h}$. After hybridization, the slides were washed twice $(1 \mathrm{~min}, 5 \mathrm{~min})$ with $2 \times \mathrm{SSC}(1 \times \mathrm{SSC}$ is $0.15 \mathrm{M} \mathrm{NaCl}$ plus $0.015 \mathrm{M}$ sodium citrate $)$ and $0.1 \%$ sodium dodecyl sulfate $(\mathrm{SDS})\left(42^{\circ} \mathrm{C}\right)$, once $(10 \mathrm{~min})$ with $0.1 \times \mathrm{SSC}$ and $0.1 \% \operatorname{SDS}\left(20^{\circ} \mathrm{C}\right)$, three times $(15 \mathrm{~s}, 2 \mathrm{~min}$, $1 \mathrm{~min})$ with $0.1 \times \mathrm{SSC}\left(20^{\circ} \mathrm{C}\right)$, and once $(10 \mathrm{~s})$ with $0.01 \times \mathrm{SSC}$ $\left(20^{\circ} \mathrm{C}\right)$. The slides were dried by a short centrifugation and were stored in a dry, dark chamber prior to scanning.

\section{Statistical analysis of microarray data.}

Fluorescence intensities were measured using an Axon 4000A laser scanner, followed by conversion of images into digital values using GenePix Pro software (3.0.6.89) (Axon Laboratories, Union City, CA, U.S.A.). Data images were inspected manually, and low-quality spots were excluded before further analysis. For those spots remaining, the raw fluorescence intensities for each channel on each slide were collected. The entire dataset was then divided into two subdatasets, one for fungal and one for plant reporters, to allow independent normalizations and analyses. For each channel, the mean background fluorescence was calculated. After local background correction for each spot, the reporters yielding intensities below twice the background were excluded and the fluorescence for the reporters remaining was multiplied to give a common channel mean of 5,000 fluorescence units in each hybridization. As a result, data for 1,041 fungal and 1,063 plant genes remained in the dataset. Data was statistically analyzed, by using a mixed-model ANOVA, to rank the effects of time and tissue on transcription (Wolfinger et al. 2001). This procedure uses differences in normalized expression levels rather than ratios as the unit of analysis of expression differences. We subjected the corrected $\log _{2}$-transformed measures $\left(y_{g i j}\right)$ for the fungal gene $g(g=1, \ldots, 1,041)$ and the plant gene $g$ ( $g=1, \ldots, 1,063)$ which included scores for 114,774 fungal spot measures and 89,043 plant spot measures to a normalization model of the form $y_{g i j}=\mu+A_{i}+D_{j}+$ $(A \times D)_{i j}+\varepsilon_{g i j}$, where $\mu$ is the sample mean, $A_{i}$ is the effect of the $i$ th array $\left(i=1\right.$ to 20), $D_{j}$ is the effect of the $j$ th dye (Cy3 or Cy5), $(A \times D)_{i j}$ is the array-dye interaction (channel effect), and $\varepsilon_{g i j}$ is the stochastic error. We then subjected the residuals from this model, which can be regarded as a crude indicator of relative expression level (and are referred to in the text as "normalized gene expression levels") to 1,041 fungal and 1,063 plant gene-specific models of the form $r_{i j l m}=\mu+A_{i}+$ $T_{l}+U_{m}+D_{j}+(T \times U)_{l m}+\varepsilon_{i j l m}$, where $T_{l}$ is the $l$ th time of synthesis $(2,4,8,14$, and 21 days; 4 degrees of freedom [d.f.]), $U_{m}$ is the $m$ th tissue (ECM or reference tissue; 1 d.f.) and $(T \times U)_{l m}$ is the interaction between tissue and days of synthesis $(1$ d.f.). In the gene models, which were fitted using PROC MIXED in SAS (SAS/STAT Software Version 8; SAS Institute Inc., Cary, NC, U.S.A.), the $A_{i}$ variable controls for spot effects and is random (19 d.f., leaving 13 d.f. for the residual error). The microarray raw dataset (accession number E-MEXP-180) is available at the EMBL-EBI ArrayExpress database. 
Clustering analyses of microarray data.

For clustering analyses we used Cluster 3.0 software and for viewing, Java TreeView software.

\section{DNA sequencing.}

For complete DNA sequencing of cDNAs representing candidate genes, plasmid clones were collected from a collection of EST libraries constructed in the pTriplEx2 vector (BD Clontech, Palo Alto, CA, U.S.A.) and maintained as bacterial lysates (Johansson et al. 2004). The bacterial lysate was used for retransformation into Escherichia coli $\mathrm{DH} 5 \alpha$, and transformants were verified by standard procedures. Plasmids were prepared and used as starting material for DNA sequencing, using the dideoxy chain-termination method (Sanger et al. 1977), employing the BigDye Terminator kit (Applied Biosystems, Stockholm, Sweden) and either using the pTriplEx2-specific universal forward primer P104 (5'-GGGAAGCGCGCCA TTGTGTT- $\left.3^{\prime}\right)$, the reverse primer T23V $\left(5^{\prime}-\mathrm{T}_{23} \mathrm{~V}-3^{\prime}, \mathrm{V}=\mathrm{A}, \mathrm{G}\right.$ or $\mathrm{C}$ ), or template-specific primers. A standard cycling protocol was followed (Applied Biosystems). The products were purified by isopropanol precipitation and, finally, were loaded onto an ABI3100 DNA sequencer (Applied Biosystems).

\section{Real-time QPCR.}

For validation of microarray data, QPCR analyses were performed on five different target genes (Table 3), using reversetranscribed aRNA as templates. aRNA preparations representing the ECM tissue at each timepoint and for each biological replicate, as also used for the microarray analysis, were reverse transcribed into cDNA using TaqMan reverse transcription reagents (Applied Biosystems). For each sample, $100 \mathrm{ng}$ of aRNA was reverse transcribed, using random hexamer oligonucleotides as primers, in a total volume of $10 \mu \mathrm{l}$, in accordance with the manufacturer's instructions. Produced cDNA was diluted 1:20 and was used as template for QPCR analysis. Primers for QPCR were designed using Vector NTI Suite 7 software (Invitrogen AB, Stockholm, Sweden), and the following criteria were set: product size, 150 to $200 \mathrm{bp}$ and melting temperature, $60 \pm 1^{\circ} \mathrm{C}$. Primers are listed in Table 3 .

Each QPCR reaction ( $25 \mu$ l total volume) contained $1 \mu \mathrm{l}$ of diluted template, $100 \mathrm{nM}$ of each primer, and $1 \times$ SYBR green PCR master mix (Applied Biosystems). Reactions for each template and each target were run in triplicate, using the Mx3000P real-time PCR system (Stratagene, Amsterdam). The ROX dye was used as a passive reference, and the following cycling parameters were applied: $95^{\circ} \mathrm{C}$ for $10 \mathrm{~min}$, and then, 55 cycles of $95^{\circ} \mathrm{C}$ for $30 \mathrm{~s}, 60^{\circ} \mathrm{C}$ for $1 \mathrm{~min}$, and $72^{\circ} \mathrm{C}$ for $30 \mathrm{~s}$. No-template controls were run for each primer pair.

For data analysis, triplicate measures ( $\mathrm{Ct}$ values) for each template (ECM tissue for three biological replicates at five different timepoints) and each target were averaged followed by averaging data for all three biological replicates. For targets analyzed (Table 3 ), the hetC1 transcript was used as a normalizer to relatively quantify a fold difference between expression levels for the target and normalizer gene at each timepoint. The PCR efficiency was assumed to be $100 \%$ and fold differences were calculated by using the $\Delta \Delta \mathrm{Ct}$ method provided by the Mx3000P software (Stratagene). For the purpose of scaling, the fold value for the first timepoint (2 days) was used as a calibrator.

For the comparison of microarray and QPCR data, normalized $\log _{2}$ expression levels representing the ECM tissue for each target and at each timepoint were extracted from the microarray dataset, and after antilog transformation, fold differences were calculated for each target and at each timepoint using the hetCl transcript as a normalizer. As for QPCR data, the day 2 data was used for calibration (Fig. 6).

\section{ACKNOWLEDGMENTS}

We wish to thank B. Rajashekar and B. Canbäck for their kind help on bioinformatics issues, A.-M. Sonnerfeldt and H. Rouhier for tissue embedding and microscopy, and F. Lapeyrie and F. Martin for discussions on the experimental design. This study was supported by grants from the Swedish Research Council. Custom cDNA microarrays were produced at the SWEGENE DNA Microarray Resource Centre, at the BioMedical Center B19 in Lund, and DNA sequencing was performed at the SWEGENE Center of Genomic Ecology at the Ecology Building in Lund, financially supported by the Knut and Alice Wallenberg foundation through the SWEGENE consortium.

\section{LITERATURE CITED}

Barker, S. J., Tagu, D., and Delp, G. 1998. Regulation of root and fungal morphogenesis in mycorrhizal symbiosis. Plant Physiol. 116:12011207.

Bernier, F. and Berna, A. 2001. Germins and germin-like proteins: Plant do-all proteins. But what do they do exactly? Plant Physiol. Biochem. 39:545-554.

Birkenfeld, J., Betz, H., and Roth, D. 2003. Identification of cofilin and LIM-domain-containing protein kinase 1 as novel interaction partners of 14-3-3 . Biochem J. 369:45-54.

Bolle, C. 2004. The role of GRAS proteins in plant signal transduction and development. Planta 218:683-692.

Brun, A., Chalot, M., Finlay, R. D., and Söderström, B. 1995. Structure and function of the ectomycorrhizal association between Paxillus involutus (Batsch) Fr. and Betula pendula (Roth.). I. Dynamics of mycorrhiza formation. New Phytol. 129:487-493.

Brundrett, M. C., Piché, Y., and Peterson, R. L. 1984. A new method for observing the morphology of vesicular-arbuscular mycorrhizae. Can. J. Bot. 63:2128-2134.

Bugos, R. C., Chiang, V. L., Zhang, X. H., Campbell, E. R., Podila, G. K., and Campbell, W. H. 1995. RNA isolation from plant tissues recalcitrant to extraction in guanidine. BioTechniques 19:734-737.

Busam, G., Junghanns, K. T., Kneusel, R. E., Kassemeyer, H. H., and Matern, U. 1997. Characterization and expression of caffeoyl-coenzyme A 3-O-methyltransferase proposed for the induced resistance response of Vitis vinifera L. Plant Physiol. 115:1039-1048.

Carnero Diaz, E., Martin, F., and Tagu, D. 1996. Eucalypt $\alpha$-tubulin: cDNA cloning and increased level of transcripts in ectomycorrhizal root system. Plant Mol. Biol. 31:905-910.

Collinge, D. B., Kragh, K. M., Mikkelsen, J. D., Nielsen, K. K., Rasmussen, U., and Vad, K. 1993. Plant chitinases. Plant J. 3:31-40.

Culley, D. E., Horovitz, D., and Hadwiger, L. A. 1995. Molecular characterization of disease-resistance response gene DRR206-d from Pisum sativum (L.). Plant Physiol. 107:301-302.

Curran, S. P., Leuenberger, D., Oppliger, W., and Koehler, C. M. 2002. The Tim9p-Tim10p complex binds to the transmembrane domains of the ADP/ATP carrier. EMBO (Eur. Mol. Biol. Organ.) J. 21:942-953.

Davies, F. T., Jr., Svenson, S. E., Cole, J. C., Phavaphutanon, L., Duray, S. A., Olalde-Portugal, V., Meier, C. E., and Bo, S. H. 1996. Non-nutritional stress acclimation of mycorrhizal woody plants exposed to drought. Tree Physiol. 16:985-993.

Davin, L. B., and Lewis, N. G. 2000. Dirigent proteins and dirigent sites explain the mystery of specificity of radical precursor coupling in lignan and lignin biosynthesis. Plant Physiol. 123:453-462.

Day, R. B., Shibuya, N., and Minami, E. 2003. Identification and characterization of two new members of the GRAS gene family in rice responsive to $N$-acetylchitooligosaccharide elicitor. Biochim. Biophys. Acta 1625:261-268.

Devenish, R. J., Prescott, M., Roucou, X., and Nagley, P. 2000. Insights into ATP synthase assembly and function through the molecular genetic manipulation of subunits of the yeast mitochondrial enzyme complex. Biochim. Biophys. Acta 1458:428-442.

Doll, J., Hause, B., Demchenko, K., Pawlowski, K., and Krajinski, F. 2003. A member of the germin-like protein family is a highly conserved mycorrhiza-specific induced gene. Plant Cell Physiol. 44:1208-1214.

dos Remedios, C. G., Chhabra, D., Kekic, M., Dedova, I. V., Tsubakihara, M., Berry, D. A., and Nosworthy, N. J. 2003. Actin binding proteins: Regulation of cytoskeletal microfilaments. Physiol. Rev. 83:433-473.

Duplessis, S., Courty, P. E., Tagu, D., and Martin, F. 2005. Transcript patterns associated with ectomycorrhiza development in Eucalyptus globulus and Pisolithus microcarpus. New Phytol. 165:599-611.

Finlay, R. D., and Söderström, B. 1992. Mycorrhiza and carbon flow to the soil. Pages 134-160 in: Mycorrhizas functioning. M. Allen, ed. Chapmann and Hall, London. 
Garcia-Garrido, J. M., and Ocampo, J. A. 2002. Regulation of the plant defence response in arbuscular mycorrhizal symbiosis. J. Exp. Bot. 53:1377.

Gopalan, S., Wei, W., and He, S. Y. 1996. hrp gene-dependent induction of hin1: A plant gene activated rapidly by both harpins and the avrPto gene-mediated signal. Plant J. 10:591-600.

Gorfer, M., Tarkka, M. T., Hanif, M., Pardo, A. G., Laitiainen, E., and Raudaskoski, M. 2001. Characterization of small GTPases Cdc42 and $\mathrm{Rac}$ and the relationship between $\mathrm{Cdc} 42$ and actin cytoskeleton in vegetative and ectomycorrhizal hyphae of Suillus bovinus. Mol. PlantMicrobe Interact. 14:135-144.

Harris, S. D., and Momany, M. 2004. Polarity in filamentous fungi: Moving beyond the yeast paradigm. Fungal Genet. Biol. 41:391-400.

Heil, M., and Bostock, R. M. 2002. Induced systemic resistance (ISR) against pathogens in the context of induced plant defences. Ann. Bot. (Lond) 89:503-512.

Hibbett, D. S., Gilbert, L.-B., and Donoghue, M. J. 2000. Evolutionary instability of ectomycorrhizal symbiosis in basidiomycetes. Nature 407:506508

Horan, D. P., Chilvers, G. A., and Lapeyrie, F. F. 1988. Time sequence of the infection process in eucalypt ectomycorrhizas. New Phytol. 109:451-458.

Javot, H., and Maurel, C. 2002. The role of aquaporins in root water uptake. Ann. Bot. (Lond) 90:301-313

Jin, W., Riley, R. M., Wolfinger, R. D., White, K. P., Passador-Gurgel, G., and Gibson, G. 2001. The contributions of sex, genotype and age to transcriptional variance in Drosophila melanogaster. Nat. Genet. 29:389-395.

Johansson, T., Le Quéré, A., Ahren, D., Söderström, B., Erlandsson, R., Lundeberg, J., Uhlén, M., and Tunlid, A. 2004. Transcriptional responses of Paxillus involutus and Betula pendula during formation of ectomycorrhizal root tissue. Mol. Plant-Microbe Interact. 17:202-215.

Kamiya, N., Itoh, J., Morikami, A., Nagato, Y., and Matsuoka, M. 2003. The SCARECROW gene's role in asymmetric cell divisions in rice plants. Plant J. 36:45-54.

Kim, C. Y., Lee, S. H., Park, H. C., Bae, C. G., Cheong, Y. H., Choi, Y. J., Han, C., Lee, S. Y., Lim, C. O., and Cho, M. J. 2000. Identification of rice blast fungal elicitor-responsive genes by differential display analysis. Mol Plant-Microbe Interact 13:470-474.

Kombrink, E., and Schmelzer, E. 2001. The hypersensitive response and its role in local and systemic disease resistance. Eur. J. Plant Pathol. 107:69-78.

Lamb, C., and Dixon, R. A. 1997. The oxidative burst in plant disease resistance. Annu. Rev. Plant Physiol. Plant Mol. Biol. 48:251-275.

Laurent, P., Voiblet, C., Tagu, D., de Carvalho, D., Nehls, U., De Bellis, R., Balestrini, R., Bauw, G., Bonfante, P., and Martin, F. 1999. A novel class of ectomycorrhiza-regulated cell wall polypeptides in Pisolithus tinctorius. Mol. Plant-Microbe Interact. 12:862-871.

Le Quéré, A., Schützendübel, A., Rajashekar, B., Canbäck, B., Hedh, J., Erland, S., Johansson, T., and Tunlid, A. 2004. Divergence in gene expression related to variation in host specificity of an ectomycorrhizal fungus. Mol. Ecol. 13:3809-3819.

Li, L., Cheng, X. F., Leshkevich, J., Umezawa, T., Harding, S. A., and Chiang, V. L. 2001. The last step of syringyl monolignol biosynthesis in angiosperms is regulated by a novel gene encoding sinapyl alcohol dehydrogenase. Plant Cell 13:1567-1586.

Malajczuk, N., Lapeyrie, F., and Garbaye, J. 1990. Infectivity of pine and eucalypt isolates of Pisolithus tinctorius on roots of Eucalyptus urophylla in vitro. 1. Mycorrhiza formation in model systems. New Phytol. 114:627-631.

Malloch, D. W., Pirozynski, K. A., and Raven, P. H. 1980. Ecological and evolutionary significance of mycorrhizal symbioses in vascular plants (a review). Proc. Natl. Acad. Sci. U.S.A. 77:2113-2118.

Markovic-Housley, Z., Degano, M., Lamba, D., Roepenack-Lahaye, E., Clemens, S., Susani, M., Ferreira, F., Scheiner, O., and Breiteneder, H. 2003. Crystal structure of a hypoallergenic isoform of the major birch pollen allergen Bet v 1 and its likely biological function as a plant steroid carrier. J. Mol. Biol. 325:123-133.

Martin, F., Laurent, P., de Carvalho, D., Voiblet, C., Balestrini, R., Bonfante, P., and Tagu, D. 1999. Cell wall proteins of the ectomycorrhizal basidiomycete Pisolithus tinctorius: Identification, function, and expression in symbiosis. Fungal Genet. Biol. 27:161-174.

Massicotte, H. B., Peterson, R. L., and Ashford, A. E. 1987. Ontogeny of Eucalyptus pilularis-Pisolithus tinctorius ectomycorrhizae. I. Light microscopy and scanning electron microscopy. Can. J. Bot. 65:1927-1939.

Menotta, M., Amicucci, A., Sisti, D., Gioacchini, A. M., and Stocchi, V. 2004. Differential gene expression during pre-symbiotic interaction between Tuber borchii Vittad. and Tilia americana L. Curr. Genet. 46:158-165.
Morel, M., Jacob, C., Kohler, A., Johansson, T., Martin, F., Chalot, M., and Brun, A. 2005. Identification of genes differentially expressed in extraradical mycelium and ectomycorrhizal roots during Paxillus involutusBetula pendula ectomycorrhizal symbiosis. Appl. Environ. Microbiol. 71:382-391.

Nehls, U., Wiese, J., Guttenberger, M., and Hampp, R. 1998. Carbon allocation in ectomycorrhizas: Identification and expression analysis of an Amanita muscaria monosaccharide transporter. Mol. Plant-Microbe Interact. 11:167-176.

Nehls, U., Bock, A., Ecke, M., and Hampp, R. 2001. Differential expression of the hexose-regulated fungal genes AmPAL and AmMst1 within Amanita/Populus ectomycorrhizas. New Phytol. 150:583-589.

Niini, S. S., Tarkka, M. T., and Raudaskoski, M. 1996. Tubulin and actin protein patterns in Scots pine (Pinus sylvestris) roots and developing ectomycorrhiza with Suillus bovinus. Physiol. Plant 96:186-192.

Nylund, J.-E., and Unestam, T. 1982. Structure and physiology of ectomycorrhizae. I. The process of mycorrhiza formation in Norway spruce in vitro. New Phytol. 91:63-79.

Padmanabhan, V., Dias, D. M., and Newton, R. J. 1997. Expression analysis of a gene family in loblolly pine (Pinus taeda L.) induced by water deficit stress. Plant Mol. Biol. 35:801-807.

Peter, M., Courty, P. E., Kohler, A., Delaruelle, C., Martin, D., Tagu, D., Frey-Klett, P., Duplessis, S., Chalot, M., Podila, G., and Martin, F. 2003. Analysis of expressed sequence tags from the ectomycorrhizal basidiomycetes Laccaria bicolor and Pisolithus microcarpus. New Phytol. 159:117-129.

Podila, G. K., Balasubramanian, S. S., Hiremath, J. H., Brans, J. H., and Hymes, M. J. 2002. Fungal gene expression in early symbiotic interactions between Laccaria biclor and red pine. Plant Soil 244:117-128.

Robertson, M. 2003. Increased dehydrin promoter activity caused by HvSPY is independent of the ABA response pathway. Plant J. 34:39-46.

Sanger, F., Nicklen, S., and Coulson, A. R. 1977. DNA sequencing with chain-terminating inhibitors. Proc. Natl. Acad. Sci. U.S.A. 74:5463-5467.

Schaeffer, C., Wallenda, T., Guttenberger, M., and Hampp, R. 1995. Acid invertase in mycorrhizal and non-mycorrhizal roots of Norway spruce (Picea abies [L.] Karst.) seedlings. New Phytol. 129:417-424.

Schäffner, A. R. 1998. Aquaporin function, structure, and expression: Are there more surprises to surface in water relations? Planta 204:131-139.

Shi, L., Guttenberger, M., Kottke, I., and Hampp, R. 2002. The effect of drought on mycorrhizas of beech (Fagus sylvatica L.): Changes in community structure, and the content of carbohydrates and nitrogen storage bodies of the fungi. Mycorrhiza 12:303-311.

Smith, S. E. and Read, D. J. 1997. Mycorrhizal Symbiosis. 2nd ed. Academic Press, San Diego, CA, U.S.A

Sundaram, S., Kim, S. J., Suzuki, H., Mcquattie, C. J., Hiremah, S. T., and Podila, G. K. 2001. Isolation and characterization of a symbiosis-regulated ras from the ectomycorrhizal fungus Laccaria bicolor. Mol. Plant-Microbe Interact. 14:618-628.

Tagu, D., and Martin, F. 1996. Molecular analysis of cell wall proteins expressed during the early steps of ectomycorhiza development. New Phytol. 133:73-85.

Tagu, D., Nasse, B., and Martin, F. 1996. Cloning and characterization of hydrophobins-encoding cDNAs from the ectomycorrhizal basdiomycete Pisolithus tinctorius. Gene 168:93-97.

Tagu, D., De Bellis, R., Balestrini, R., De Vries, O. M. H., Piccoli, G., Stocchi, V., Bonfante, P., and Martin, F. 2001. Immunolocalization of hydrophobin HYDPt-1 from the ectomycorrhizal basidiomycete $P i$ solithus tinctorius during colonization of Eucalyptus globulus roots. New Phytol. 149:127-135.

Tagu, D., Lapeyrie, F., and Martin, F. 2002. The ectomycorrhizal symbiosis: Genetics and developments. Plant Soil 244:97-105.

Tagu, D., Palin, B., Balestrini, R., Gelhaye, E., Lapeyrie, F., Jacquot, J. P. Sautiere, P. E., Bonfante, P., and Martin, F. 2003. Characterization of a symbiosis- and auxin-regulated glutathione-S-transferase from Eucalyptus globulus roots. Plant Physiol. Biochem. 41:611-618.

Tian, Z. D., Liu, J., Xie, C. H., and Song, B. T. 2003. Cloning of potato POTHR-1 gene and its expression in response to infection by Phy tophthora infestans and other abiotic stimuli. Acta Bot. Sin. 45:959-965.

Timonen, S., Finlay, R. D., Söderström, B., and Raudaskoski, M. 1993. Identification of cytoskeletal components in pine ectomycorrhizas. New Phytol. 124:83-92.

van Loon, L. C., and van Strien, E. A. 1999. The families of pathogenesisrelated proteins, their activities, and comparative analysis of PR-1 type proteins. Physiol. Mol. Plant Pathol. 55:85-97.

Voiblet, C., Duplessis, S., Encelot, N., and Martin, F. 2001. Identification of symbiosis-regulated genes in Eucalyptus globulus-Pisolithus tinctorius ectomycorrhiza by differential hybridization of arrayed cDNAs. Plant J. 25:181-191.

Wang, E., Miller, L. D., Ohnmacht, G. A., Liu, E. T., and Marincola, F. M. 
2000. High-fidelity mRNA amplification for gene profiling. Nat. Biotechnol. 18:457-459.

Welling, A., Rinne, P., Vihera-Aarnio, A., Kontunen-Soppela, S., Heino, P., and Palva, E. T. 2004. Photoperiod and temperature differentially regulate the expression of two dehydrin genes during overwintering of birch (Betula pubescens Ehrh.). J. Exp. Bot. 55:507-516.

Wolfinger, R. D., Gibson, G., Wolfinger, E. D., Bennett, L., Hamadeh, H., Bushel, P., Afshari, C., and Paules, R. S. 2001. Assessing gene significance from cDNA microarray expression data via mixed models. J. Comput. Biol. 8:625-637.
AUTHOR-RECOMMENDED INTERNET RESOURCES

The European Bioinformatics Institute EMBL-EBI ArrayExpress database: www.ebi.ac.uk/arrayexpress

Stanford University School of Medicine protocol for mRNA amplification and target preparation webpage:

cmgm.stanford.edu/pbrown/protocols/ampprotocol_3.html

Cluster 3.0 software: bonsai.ims.u-tokyo.ac.jp/ mdehoon/software/cluster Java TreeView software: genome-www.stanford.edu/ alok/TreeView 